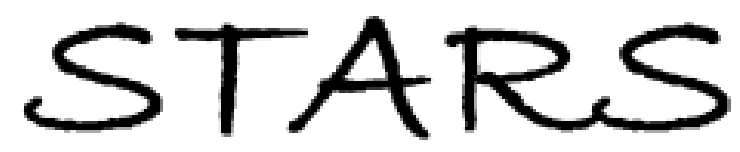

University of Central Florida

STARS

$1-1-2006$

\title{
Structural health monitoring of bridges for improving transportation security
}

\author{
F. Necati Catbas \\ University of Central Florida \\ Melih Susoy \\ University of Central Florida \\ Naim Kapucu \\ University of Central Florida
}

Find similar works at: https://stars.library.ucf.edu/facultybib2000

University of Central Florida Libraries http://library.ucf.edu

This Article is brought to you for free and open access by the Faculty Bibliography at STARS. It has been accepted for inclusion in Faculty Bibliography 2000 s by an authorized administrator of STARS. For more information, please contact STARS@ucf.edu.

\section{Recommended Citation}

Catbas, F. Necati; Susoy, Melih; and Kapucu, Naim, "Structural health monitoring of bridges for improving transportation security" (2006). Faculty Bibliography 2000s. 6008.

https://stars.library.ucf.edu/facultybib2000/6008

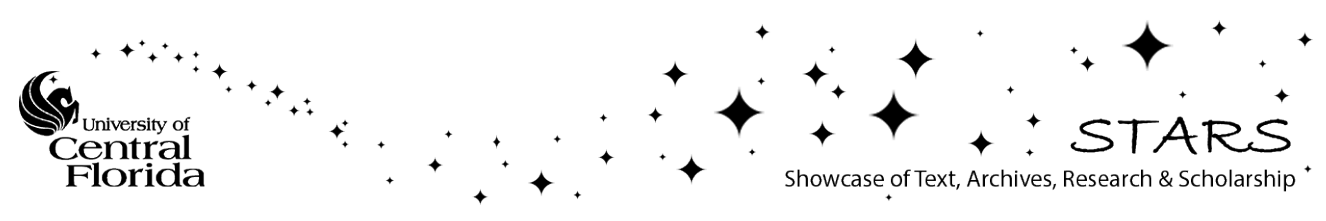




\section{Journal of Homeland Security and Emergency Management}

Volume 3, Issue 4 2006

Article 13

\section{Structural Health Monitoring of Bridges for Improving Transportation Security}

F. Necati Catbas, Civil and Environmental Engineering Department, University of Central Florida Melih Susoy, Civil and Environmental Engineering Department, University of Central Florida

Naim Kapucu, Department of Public Administration, University of Central Florida

Recommended Citation:

Catbas, F. Necati; Susoy, Melih; and Kapucu, Naim (2006) "Structural Health Monitoring of Bridges for Improving Transportation Security," Journal of Homeland Security and Emergency Management: Vol. 3: Iss. 4, Article 13.

DOI: $10.2202 / 1547-7355.1217$ 


\title{
Structural Health Monitoring of Bridges for Improving Transportation Security
}

\author{
F. Necati Catbas, Melih Susoy, and Naim Kapucu
}

\begin{abstract}
Structural health monitoring (SHM) is a promising technology for determining the condition of significant transportation structures objectively for efficient management and preservation of transportation assets. In addition to identifying, locating, and quantifying damage and deterioration due to effects of operation, aging, and natural hazards, the need for taking terrorismrelated hazards into account has become evident after 9/11 terrorist attacks. Key transportation facilities like major bridges were identified by Department of Homeland Security (DHS) as possible terrorist targets since their loss or even temporary deficiency could lead to major impacts on economy and mobility. Several governmental, local, and private organizations have been working on identifying possible modes of threats, determining and sorting vulnerable structures, and establishing ways to prevent, detect and respond to such attacks. Authorities are also investigating ways to integrate current and future bridge management systems with security surveillance systems. Highway bridges are key links of the transportation system. This paper reviews security measures for bridges and discuss possible integration of structural health and security monitoring for improving security and safety of bridges and emergency management after a natural or man-made disaster.
\end{abstract}

KEYWORDS: structural health monitoring, bridges, transportation systems, transportation security, emergency management

Author Notes: The writers would like to express their sincere gratitude to Prof. A. Emin Aktan (Drexel University) and Prof. Louise K. Comfort (University of Pittsburgh) for their pursuit of multidisciplinary studies which motivated the writers for this paper. Also, the writers would like to thank Ms. Sheila Duwadi, Dr. Steven Chase and Dr Hamid Ghasemi from Federal Highway Administration for their guidance on introducing new technologies for improving bridge security and long-term performance. Finally, the anonymous reviewers all provided valuable contribution with their ideas, and provided important feedback for the paper. 


\section{INTRODUCTION}

In 1997, the nation's transportation system was identified by Presidential Commission on Critical Infrastructure Protection (PCCIP 1997) as one of eight systems as critical infrastructure. Within the entire transportation system, highway transportation infrastructure is a sub-system with approximately 600,000 bridges, 160,000 miles of interstate and national highway roads and 200 tunnels (Duwadi 2003; Duwadi and Chase 2006). Problems for such a large and complex system require a systems approach for comprehensive analysis of mobility, efficiency, safety, and integrity.

Issues related to security of the transportation system have been discussed more often after the 9/11 terrorist attacks. The White House Report on protecting the infrastructure assets vital to national security, safety, economy, and public confidence against terrorist attacks identifies safeguarding transportation systems as one of the critical mission areas (The White House Report 2003). The task of securing the nation's transportation systems was assigned to newly established Transportation Security Administration (TSA) which is part of the Department of Homeland Security (DHS). TSA will work closely with Department of Transportation (DOT). Under the guidance of TSA, transportation officials in all regions are investigating ways to incorporate security considerations into their infrastructure and traffic management systems. Many state DOTs are working closely with their state and county emergency management agencies to better adapt the statewide plans to the challenges of terrorism and are currently in the process of updating their comprehensive emergency management plans. Some of these activities indicate an increased role for transportation to capitalize on DOTs distributed personnel, incident response training, and statewide communications networks. Furthermore, state DOTs are increasing their capacity to monitor and view highway conditions as well as apply management and communications facilities to support emergency movement of people and goods during and after emergencies and crises (SAIC 2002a).

Recently, Science and Technology Directorate of the DHS declared that transportation systems are among the critical infrastructure to be protected. The critical infrastructure protection (CIP) plan lays out strategies for development and implementation of security systems capable of providing satisfactory protection for transportation assets (DHS 2004).

In order to provide solutions for the transportation systems, it is important to first review various components. Critical infrastructure represents interdependent technical and organizational systems that are essential for maintaining economic, social and cultural activities of human settlements. These systems are vulnerable to a range of hazards: natural, technological, and manmade. A generic description of "system” may be defined as "a regularly interacting or interdependent group of 
elements forming a unified whole” (Aktan and Faust 2003). When we consider the highway transportation infrastructure, there are major interacting and interdependent components as illustrated in Figure 1:

- Engineered components (bridges, roads, etc.)

- Natural components (earthquakes, hurricanes, etc.)

- Organizational components (State, local, county, etc.)

- Operational components (Infrastructure owners such as Departments of Transportation, toll road authority, law enforcement, fire department, etc.).

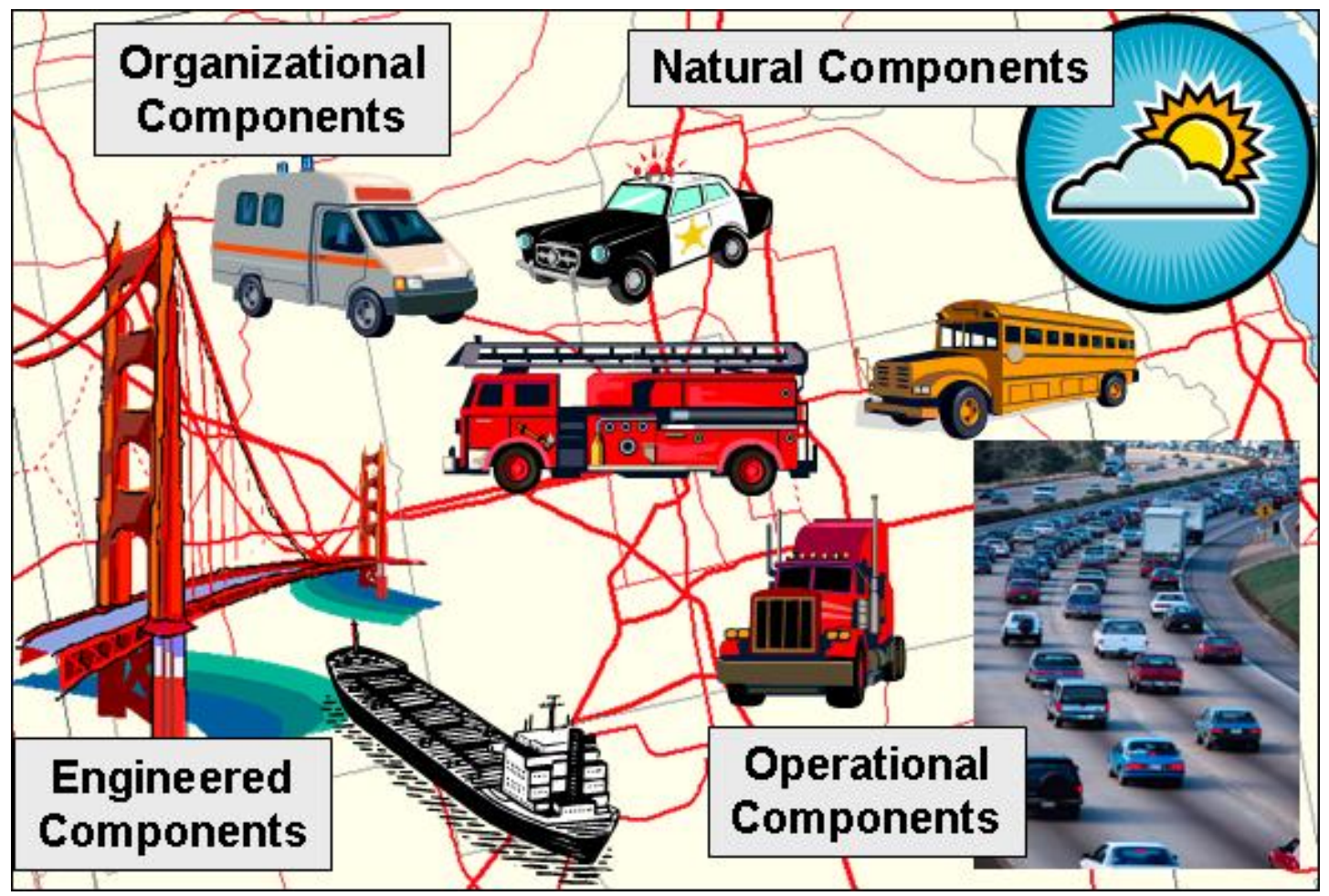

Figure 1 - Examples of Interacting and Interdependent System Components in a Metropolitan Area

Any disruption to the routine operation of these components of a transportation system due to a natural or man-made hazard can paralyze a region or even a country (Aktan and Comfort 2003). The risk of a hazard can simply be evaluated by the likelihood of it and the consequences associated with it as shown in Figure 2. This conception of risk is expressed as the product of probability (likelihood) and consequence (damage). This is represented by the curves on the 
chart as risk regions, with the curves above having higher risk. Therefore, an event would be high risk if both its probability and impact were above low levels.

For example, frequently encountered events such as fender-bender type traffic accidents on bridges might not entail significant impact on bridge safety and security. Usually, the events that cause significant impact have low frequency of occurrence (high return period) such as major earthquakes damaging bridges. These types of natural disasters affect large areas, and some may have devastating effects on the infrastructure. They are considered low-probability and high consequence events, since disaster-scale events occur rarely, but they have huge impact. Therefore, although earthquakes and extreme hurricanes have a relatively low probability of occurrence, they are high-risk events according to their high impact.

It is more difficult to define the risk for man-made disasters, since there have been major variations in the method, scale and damage than has been observed in the past. Metropolitan regions are the most frequent targets of manmade disasters and, due to their high population density and infrastructure network, the impact and consequently the risk is also expected to be high. Examples include the transportation gridlock in Los Angeles following the collapse of freeway bridges in the 1994 Northridge Earthquake and communications failure following the 2001 World Trade Center attacks in New York City. These examples illustrate the vulnerability of interconnected metropolitan regions exposed to extreme risk. The operational capacity of a complex region suffers from spreading dysfunction during a severe threat that compounds failure and creates new dangers for vulnerable populations. For manmade or natural hazards which pose threatening risks to critical infrastructure components such as bridges, it is very important to reduce the risks by carefully evaluating and mitigating vulnerabilities as well as protecting the bridges. Various measures are given in previous studies (SAIC 2002a) and additional steps can be incorporated based on the characteristics of a bridge. At the same time, the consequences in cases of hazards that do take place should be reduced by effective response and recovery.

The phenomenon of cascading failure in critical infrastructure has been observed and documented in reconnaissance studies following earthquakes (EERI reconnaissance reports 1949-2003), analyses of specific disaster events (Carley and Harrald 1997; Comfort et al. 1989; Quarantelli 1992), and systematic reviews of disaster research (Mileti 1999; Platt et al. 1999). Equally important, however, is the spread of adaptive behavior as emergency organizations learn of the damaging event, take pro-active measures to limit the spread of dysfunction and reallocate resources to restore the resiliency of communities after disasters (Quarantelli and Dynes 1977; Kauffman 1993; Kreps 1994; Simon 1981). 


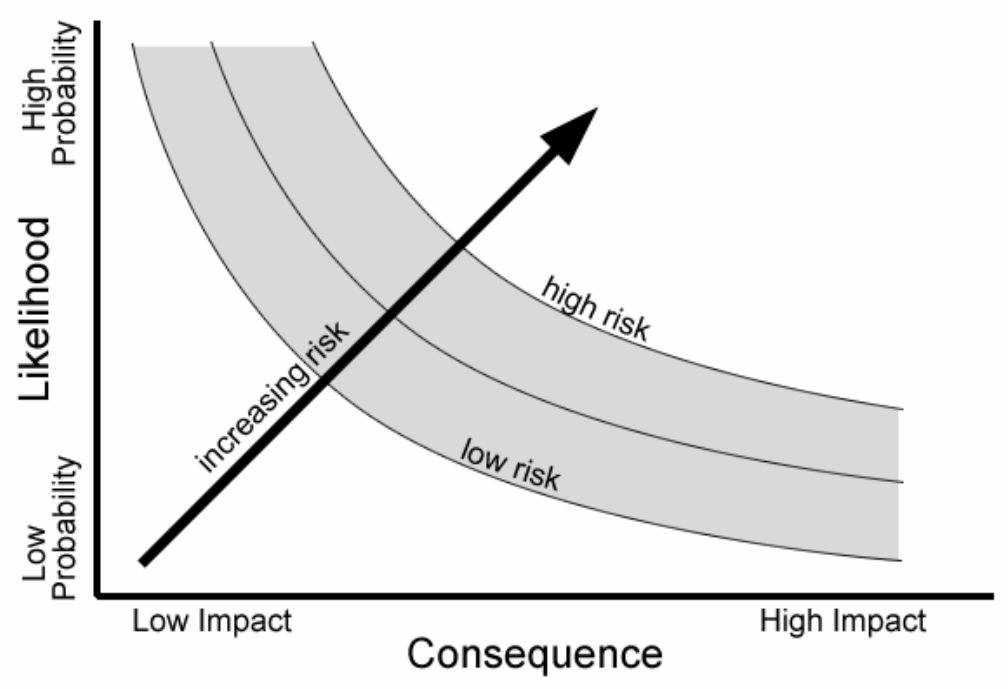

Figure 2 - Risk as Function of Likelihood and Consequence.

Loss of a critical transportation structure usually exceeds its replacement cost many times. In addition to the cost of clearing debris, interruption of infrastructure functions impacts almost all industries from finance to tourism in the interconnected area over a long period of time. The Federal Highway Administration estimated in its current report that loss of a critical bridge or tunnel could exceed $\$ 10$ billion, and a concerted attack on two or more facilities would result in a cascading effect- where the total cost would be more than the sum of individual costs (FHWA 2003).

Southeastern United States and Gulf Coast states have been experiencing devastating natural disasters since 2004. The devastation caused by Hurricane Katrina revealed the vulnerability of metropolitan regions. The horrific scenes from New Orleans and other cities are proving the importance of preparation for engineers, first responders, and the public (Figure 3). Further, there are technical and administrative issues and problems that have to be researched for managing and controlling the consequences of a disaster before, during, and after it occurs. The challenge is effectively integrating these efforts. Assembling multidisciplinary teams composed of engineers, first responders, law enforcement agencies, Emergency Medical Services (EMS), and public managers is essential. As critical nodes of the transportation network, bridges are very critical components that have to be functional during response and recovery phases after major disasters. Therefore, it is very important that the multidisciplinary teams have access to time-sensitive data to determine the type of damage to bridges. Investigation of rapid evaluation methods for emergency response operations specifically for critical vehicles such as fire trucks, ambulances, and evacuation 
buses should be conducted. Again it is evident that the primary issues confronting disasters and managing complex outcomes require communication, coordination, and integration of information from many different sources to support a coherent strategy of action for risk reduction and emergency response.

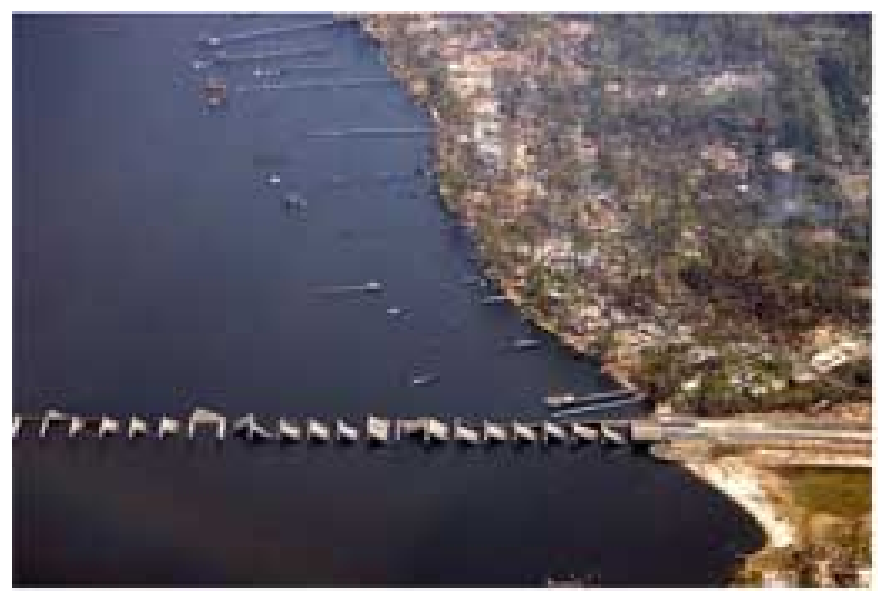

Structural bridge damage caused by Hurricane Katrina (The White House News)

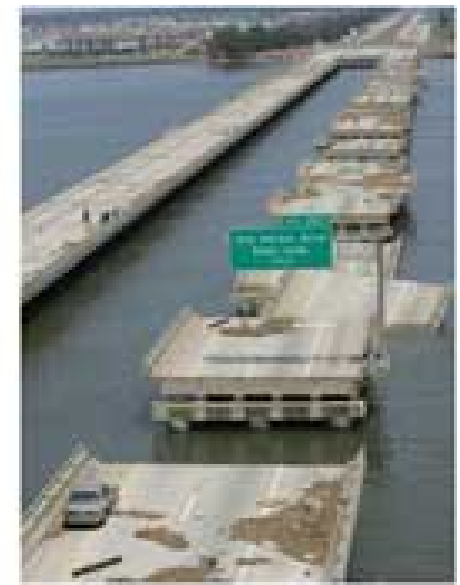

Damage to $1-10$ bridge (NBC)

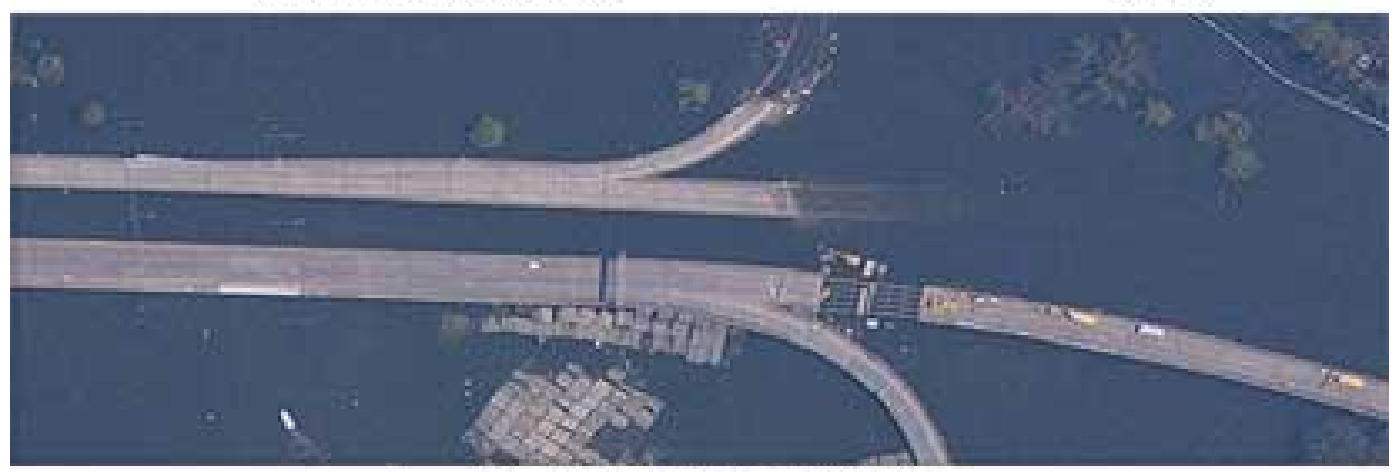

Infrastructure Damage (NOAA)

Figure 3 - Damage to Highway Bridges by Hurricane Katrina

The vulnerability of the Gulf Coast states can be characterized by frequent hurricanes, dense population, non-redundant infrastructure, and overlapping organizational structures. The catastrophic consequences of these "low probability" events underscore the need to learn as much as possible to possibly mitigate such consequences in the future. Reducing this risk is a high priority for all levels of government as stated in the National Response Plan (NRP) and this can best be accomplished by adopting an all hazards approach and emphasizing the importance of improving the capacity of first responders with the critical, 
time-sensitive data at the local level to assess and respond to risk. As a result, the importance of adopting innovative uses of information technology to increase coordination within and among jurisdictional levels to achieve timely, coherent action in risk reduction and disaster response becomes more evident. Structural health monitoring can provide the tools and technologies for gathering the data that can be used for transportation security and emergency management.

\section{SECURITY CONSIDERATIONS FOR TRANSPORTATION INFRASTRUCTURE}

Bridges are the critical nodes of the transportation system and require adequate security protection unless the associated risk level is fairly low. It is necessary to evaluate risk levels of major bridges in order to determine which structures or facilities to protect and the appropriate level of protection. It is becoming more and more important to re-define the risks since the likelihood of man-made disasters are to be re-evaluated due to evolving terrorism tactics. The main parameters of such a study are the possibility of being a target of terrorism and vulnerability of the bridge against an attack. Here the authors review the security considerations for transportation infrastructure with an emphasis on bridges. Following are the aspects of a bridge that have to be considered for risk assessment (SAIC 2002a):

- Casualty Risk - Number of users exposed as reflected in:

- The main span size of the bridge, that is, over $50 \mathrm{~m} / 165$ feet

- Traffic over 40,000 average daily traffic (ADT)

- Economic Disruption - Disruption of the national economy as indicated by:

- Bridges located on the Interstate Highway System plus the Department of Defense-defined Strategic Highway Network (STRAHNET)

- Traffic over 40,000 ADT

- Main span length over 50 meters/165 feet

- Double deck bridges

- Nearest detour distance more than 5 km/3 miles for bridges under 60,000 ADT

- Military Support Function:

- Bridges on STRAHNET and/or on the Military Traffic Management Command (MTMC)-defined "Power Projection Routes" serving forts within 400 miles of port

- Main span over 50m/165 feet

- Emergency Relief Function:

- Bridges in 78 major metropolitan areas

- On upper level system, i.e., freeways, expressways, and principal arterials 
- National Recognition:

- Bridges with symbolic importance

- Collateral Damage Exposure:

- Bridges carrying other utilities, e.g., pipelines and major power and communications lines

For assessing the vulnerability level, the first step is identifying all possible modes of threats and resulting damage types. Possible types of a terrorist attack can be listed as but not limited to (FHWA 2003):

- Low-tech and high-tech conventional explosives (e.g., shape charges)

- Explosively formed penetrating devices (EFP, kinetic energy penetrators)

- Low-tech, hand-held cutting devices

- Truck size/barge size conventional explosives

- Incendiary conventional explosives

- Intentional ramming via ship or barge (or aircraft)

Resilience of the transportation/bridge structure should be assessed for all types of attack. Preparing bridges against various types of deliberate attacks may require strengthening and/or modifying some or all structural members and installing physical obstacles, but security monitoring systems are definitely necessary where significant risk level is identified. About $70 \%$ of the state transportation agencies have an emergency response plan against terrorism incidents, but many of them are lacking adequate surveillance capability (AASHTO/TRB Initiative 2002). Currently, state DOT's and other bridge operators are employing security countermeasures against terrorism threats, and some examples of security precautions from some state DOT's include (SAIC 2002b):

- Increased security patrols

- Surveillance cameras

- Motion detection devices

- X-ray scanning

- Increased lighting

- Construction of barriers around critical members

- Removal of vegetation to provide clear lines of site

Advances in sensing technologies can also provide new alternatives for bridge monitoring for security and emergency management. There are many applicable security technologies like passive infrared (PIR) sensors which are sensitive to body heat and could be used effectively for automated intrusion detection to establish perimeter control with minimum effort and budget. 
Magnetic detection (MD) sensors detect vehicle presence, a very important element since most aggressors make use of a vehicle to attack their targets. MD sensors can help keep hostile vehicles away from vulnerable sections. Automatic Incident Detection (AID) systems are based on visual recognition algorithms over real-time video images. These systems can automatically recognize prohibited actions like vehicles stopping over bridges, suspicious behavior like unusual wandering of a person or even extraordinary events like fire, explosion, etc. Other sophisticated sensors like explosive detection within vehicles and GIS (Geographical Information Systems) technologies can also be useful for security considerations (Haupt et al. 2005; Namkoong et al. 2005; Pack and Anderson 2005).

A complete and redundant security system should be developed as a customized combination of different detection methods for retrieving more reliable and extensive monitoring data. The system should be complete by providing all the sensing, information processing and communications components while being redundant for power failures, attacks and loss of data. The system should also include automated systems for prompt and efficient alarm and reaction for protection or response. Automated systems greatly increase the surveillance capacity with minimum personnel costs and without the limitations of human factors.

\section{STRUCTURAL HEALTH MONITORING FRAMEWORK FOR SECURITY AND EMERGENCY MANAGEMENT}

Structural health monitoring (SHM) offers promise in better understanding the actual condition of the structures. SHM can be defined as continuously or intermittently monitoring of the structural systems and their components to track the condition and to identify, locate, and quantify damage. With SHM, developing condition-based maintenance strategies, prioritizing maintenance applications for better use of funds and mitigating unexpected structural problems is expected (Catbas et al. 2004a). Our focus is bridges in this paper. As a result, structural health monitoring (SHM) and bridge health monitoring (BHM) will be used interchangeably.

By integrating structural health monitoring and bridge management systems and forming a national common operating picture including decision support systems with data collection, integration, analysis, and visualization capabilities, it is possible to provide in real-time data analyses and reports on the status and security of transportation infrastructure. Interaction and administration backbone of this system can be based on Internet technology, which is to be improved and evolved as a more reliable, secure, and resilient system. A simultaneous approach is also planned to enable the structures to withstand and even automatically respond to possible attacks. 
Currently, there is a need to understand the interdependency of the transportation network components and to identify their vulnerabilities. To improve the safety and security of bridges the following issues need to be addressed:

- Identification of the critical structural elements, components and assemblies of bridges for safety and emergency management operations

- Identification of possible scenarios affecting the critical structural elements, components and assemblies

- Effects of these scenarios on traffic flow and structural condition as well as operational demands

- Identifying the vulnerabilities of the system as a whole

- Mitigation strategies for the vulnerabilities to prevent system failures

- On-line health monitoring implementation at the most vulnerable components of the system

Alternative solutions emerge as communication; sensor and Internet technologies rapidly evolve. Flexible and adaptable SHM designs are needed with respect to changing the perspective of infrastructure management requirements and possibilities. Communication, sensing, and information technologies supply effective tools for maximizing maintenance and operational efficiency. For example, it is becoming a common practice to install traffic monitoring systems either as mounted cameras or automated probes providing real-time traffic data to be used for congestion monitoring, performance evaluation, and emergency routing. Similarly, structural properties of bridges can also be retrieved with the availability of a great variety of sensors and data collection systems which are available today for relatively low prices. Bridges are transportation assets and they require regular maintenance expenditure. Asset management, as defined by American Association of State Highway and Transportation Officials (AASHTO), is a "systematic process of maintaining, upgrading, and operating physical assets cost effectively. It includes preservation, upgrading and timely replacement of assets, through cost effective management, programming, and resource allocation decisions” (AASHTO 2005). While BHM allows more efficient asset management by providing precise data for bridge safety operation and maintenance, BHM also provides time sensitive information for security and emergency management.

In Figure 4, we propose a framework that is expected to improve the bridge management, security and emergency management by incorporating BHM for bridges. This framework, if designed and implemented properly, is expected to provide time sensitive information for security and emergency management as well as for operation and maintenance. An ideal bridge management system has all management components connected as a single integrated system. The 
preferred case is that structural monitoring and traffic operation systems are linked and controlled by the same station. This way, all necessary bridge data (e.g. external forces, vibrations, stress and strain levels, traffic congestion data, GIS -Geographic Information Systems- data/information) are collected through wired or wireless networks of smart sensors, recorded, processed, and monitored in the operating station where processed information can be sent to automated systems (automated traffic signals, messages) and surveillance units when necessary. This way, bridges can be operated with optimum performance, providing the best utilization of their capacity. In addition, recording and analyzing the information from health monitoring data will lead to improvements in maintenance and structural design methods.

Management of the BHM system can directly be carried out by the local district office of DOT, which already possesses the maintenance and management responsibility of transportation infrastructure. In case of indication of an emergency situation by the surveillance system, first responders are to be alerted and coordinated by the county emergency management office through the DOT district in charge. Relationships between the county government and the local DOT and their functions should be defined according to the guidelines provided by the State Comprehensive Emergency Management Plans. National Cooperative Highway Research Program (NCHRP) has prepared an extensive report in order to assist state DOTs incorporate the guidelines drawn by the NIMS (NIMS 2004). The report identifies the needs for interagency integration, preparation and integration of emergency response plans and budgets and adaptation of required policies regarding emergency operations management. Strategies of emergency response roles of the DOT were explained within the framework of emergency management.

Recent advances in technology implementation of intelligent bridge monitoring systems are becoming readily available (Catbas et al. 2004a; Farrar et al. 2003). Although the vision of Federal Highway Administration (FHWA) and other transportation agencies is implementation of Health Monitoring Systems as standard practice of bridge management in the near future (Pagano and Ogard 2005), examples of bridge monitoring systems with highly integrated data collection and analysis are rare. Utilizing new technologies in an integrated manner and handling the massive data produced by those is a challenge, and a commonly accepted framework integrating all aspects of BHM is yet to be formulated. As more advanced monitoring tools and bridge management techniques are developed, the need for establishing standards of practice for implementing these technologies should be stressed. In developing such a framework, all components of bridge management should be considered as components of an integrated system. Infrastructure security is also a part of bridge 
management and needs to be considered within this framework of operations (Catbas et al. 2003).

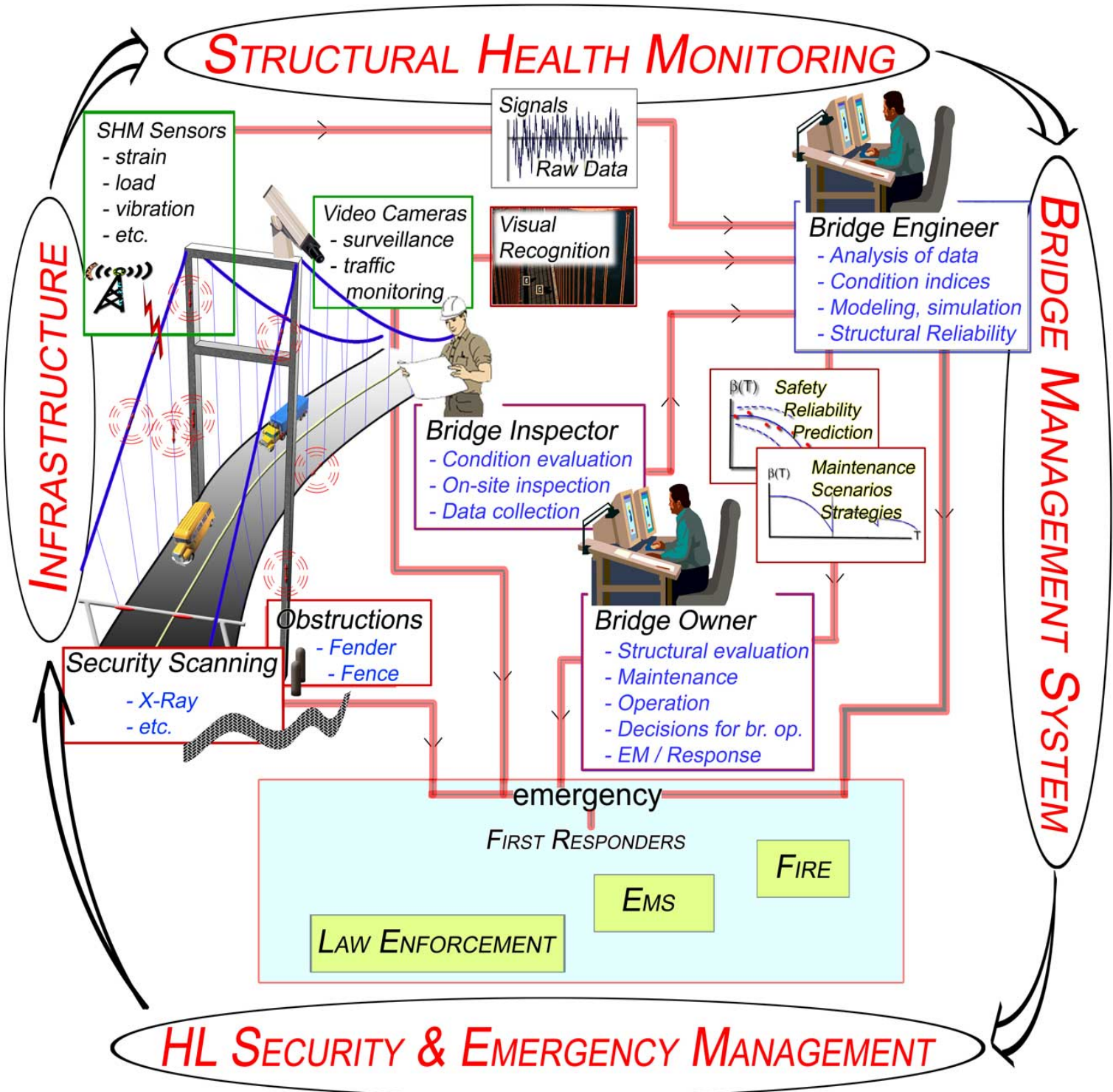

Figure 4 - Design Framework for Monitoring Systems for Bridges with Organizational and Operational Considerations 


\section{INTERRELATION BETWEEN BRIDGE MANAGEMENT AND SECURITY}

Structural monitoring, traffic surveillance, and security control systems are closely related. Security management systems have four main objectives: Prevention/mitigation, Protection, Response, and Recovery. Figure 5 outlines where bridge health monitoring (BHM) can be of great value for these objectives which are explained in more detail in the following.

Prevention/mitigation: According to the type and properties of the structure and its vulnerability to certain types of attacks, there are a number of security measures which can be chosen to deter the attacks. Other than passive defense improvements, possible security systems include video monitoring, intrusion detection, proximity sensors, vehicle content scanning and more sophisticated sensing systems. Traffic surveillance instruments already installed in many major bridges can serve to cover some of these security aspects. For example, video monitoring used for traffic congestion can also be used for security monitoring with some modifications. Security systems can also make use of other traffic monitoring systems like vehicle tracking and stopped vehicle detection.

Protection: Passive protection measures range from strengthening vulnerable sections of structures against possible hazards to erecting walls or fenders around the piers against impacts via barges or waves. Surrounding the premises with fences is also an effective approach. These passive protection measures and many others are already in use, some being standard practice. Although proven to be very beneficial, they should be considered as part of the bridge safety system, together with surveillance and monitoring measures.

Response and recovery: Responding to a man-made or natural disaster and recovering from them are crucial in minimizing damage to properties and loss of life. The key for quick and efficient response is providing instant notice of incidents by an automated system. Bridge health monitoring systems can also detect any disturbances and irregularities in structural properties and send alerts to a surveillance station for action. It is possible to modify automated bridge health monitoring systems to detect human-induced disturbances and distinguish from natural or operational disturbances. These systems are designed to inform the operators of its structural condition, and would be valuable tools for detecting the occurrence of an attack and the extent of damage caused by an attack. Prompt awareness of an attack is crucial, since fast reaction is essential to minimize the total damage. Damage assessment in the aftermath of a natural or man-made hazard can be very imperative to determining the functional safety of the structure for utilizing in emergency response. If the structural monitoring systems can

endure an attack which does not result in immediate collapse of the structure, a 
rapid evaluation of the bridge would result in decisions for either evacuation or emergency response operations. This will be a critical supplement to the damage assessment teams, which may be dispatched by the DOT or USACE. These teams are most probably overwhelmed by the number of affected structures and the extent of damage, and need to make rapid critical decisions.

Considering the aftermath of an incident, it is clear that there will be a peak demand to evacuate the area and provide emergency vehicle and personnel access, so it is imperative to keep the transportation system functional as safely and efficiently as possible. Therefore, assault detection should be integrated with traffic operations control to provide immediate data for emergency route assignments. Centrally controlled traffic information signals are indispensable for diverting the traffic to safe routes, as was done after the 9/11 attack to keep traffic away from Manhattan area in New York City. An integrated system would provide exceptional benefit in case of multiple simultaneous attacks.

In Figure 5, the four functions, prevention, protection, response and recovery, are illustrated. For these functions, specifically, the examples given above, the technological level is sufficient. Sensors and techniques that indicate the structural condition are already present (Catbas et al, 2006; Lynch and Loh, 2005, Catbas et al. 2004b; Liu and Tomizuka, 2003; Farrar et al. 2003; Catbas and Aktan 2002; Catbas et al. 1997; Levi 1997; Hogue et al. 1991), as well as automated security control systems and closed-circuit camera monitoring (CRA Report 2003; Duwadi and Chase 2006; FHWA 2003). However, the shortcomings of the current bridge management and security systems are known, and mentioned previously in this paper. The challenge is creating an integrated system, composed of embedded sensors, security monitoring, data fusion, and communication channels during routine operation and damage detection, rapid condition assessment, and automated response in an emergency. This system has to be supported by extensive risk and reliability analysis, and regulated by solving administrative issues.

Intensive studies are being carried out for identifying and reviewing the vulnerabilities, and making risk assessment related to infrastructure security (Duwadi et al. 2006; Duwadi and Chase 2006), along with mitigation measures and emergency response planning. All these studies point towards the need for an integrated approach for infrastructure management and security which is able to provide effective and quick response capabilities to minimize casualties and reducing the inflicted damage. This requires a holistic approach, as also mentioned by other studies (Jain and McLean 2006), and should be supported by technological state-of-the-art. 


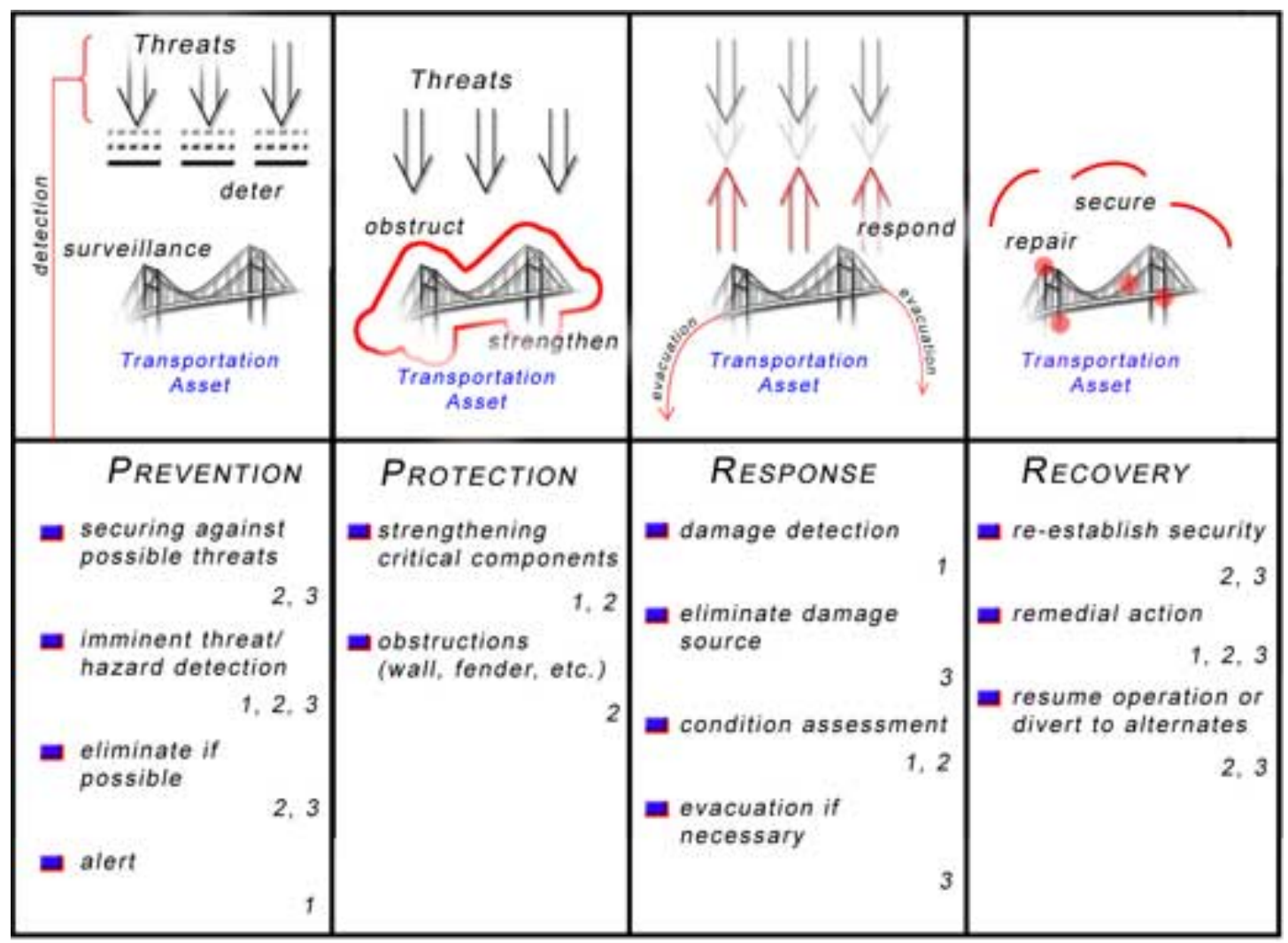

1 - Bridge Health Monitoring \& Management

2 - Infrastructure Owners/Decision Makers

3 - Emergency Response (Fire, Police, Medical)

Figure 5. Security Management by Integrated Bridge Health Monitoring, Decision Making and Emergency Response

\section{INTEGRATION OF BRIDGE SECURITY AND HEALTH MONITORING}

Bridge Health Monitoring (BHM) can provide additional tools for security monitoring through the use of sensors, information technology and analysis capabilities. For example, BHM can be designed to provide information for establishing and activating alternate routes to keep vital materials and people moving, facilitate evacuation and to allow transportation of emergency vehicle and personnel. Security management systems should be deployed as automated systems to maximize their detection and protection capability, and to provide rapid response. Terrorist attacks rely on their element of surprise, aiming to strike at vulnerable points with the least expected timing and method. One major goal of 
preparation for an aftermath response is to minimize the reaction time, which means reducing the time spent for detection, diagnosis, decision making and commencing counter action. Introducing security systems as integrated components of SHM will provide best accomplishment of security goals (TSA 2002).

Basic operating schema of security integrated BHM can be:

- Continuously monitor the system with smart sensors and detect irregular/unauthorized activity

- Security surveillance sensors (cameras, x-ray/infrared scanners, proximity alerts, etc.)

- Structural condition monitoring information (variations of stress/strain, etc.)

- Traffic management (congestion, vehicle count, vehicle tracking, etc.)

- Log surveillance data in a security database

- Review by supervisors

- Enabling information sharing between agencies

- Statistical analysis of data

- Analyze the threat and initiate response operations of appropriate level

- Locate and validate possible threat

- Send alert notification to related security/emergency units

- Prohibit access to the structure to civilian traffic and send automated messages directing vehicles to evacuate the property

- Detect structural damage and assess the condition of the bridge

- Assess the level of damage on each member (excluding total collapse case)

- Evaluate the condition of the bridge for safe functioning

- Order evacuation of the bridge to minimize casualty if the structural condition is critical and re-route the oncoming traffic

- Re-employ the bridge for emergency operations and evacuation

- Communicate with emergency response authorities

- Communicate with other transportation nodes

- Provide emergency response agencies with current data

The technologies deployed in BHM and security systems collect and aggregate data from field devices. How those data are aggregated differs according to the information needs of each respective system and its operators. To the extent possible common database applications should be specified for systems that are independently deployed in order to ease integration that may occur later. For example, some agencies consider GIS-based designs as a common 
platform/repository of device inventory and data archiving to allow customized inquiries by public safety staff, operations staff or management as any situation calls for (Port Authority of NY \& NJ 2002).

The benefits of nationwide implementation of an integrated bridge management system as described would be numerous. During ordinary operation, the system will be working with security functions; monitoring and screening for unauthorized action, while at the same time, checking the structural condition. This function will issue an alert and trigger the response functions in case of threat detection. An instant notification in case of an attack or unpredicted hazard is of extreme importance, since usually precious time is lost until emergency response teams receive the alert. Furthermore, proposed health monitoring systems are able to classify the type of the hazard, and evaluate the extent of the damage. For efficient response, the type of distress, and the current situation should be known in detail, which will be supplemented with this system in real time. Security components, such as closed circuit cameras, will also be helpful in the same manner. Before rapid damage assessment teams can be dispatched to the area, a remote structural condition assessment can be carried out for making decisions about the action, which may be to continue using the structure, or shut down to prevent further loss to infrastructure and life. The online assessment will also be helpful for planning the emergency response and evacuation operations. The system can be extended with automated on-site response functions, such as automatic gates and traffic signals.

\section{SOME ISSUES FOR INTEGRATED BRIDGE SECURITY SYSTEMS}

The main difficulty for bridge operators is the lack of guidelines for the implementation of the security systems. The state DOT's are overwhelmed by the evaluation process for new technologies: the decision process for which system to install, valuable time and money is to be spent. It is also clear that the state DOT's do not have sufficient funds or man-power for acquiring and evaluating all the latest technologies to select proper systems and use them for their routine and emergency operations. There is a need for studies and guidelines that can facilitate the identification of best practices. Also, there is a need for improved cooperation among federal, state and local government agencies to provide best system for surveillance and security.

Differences in application practice were identified between different states implementing security measures to their bridges, with some states having designed and installed systems superior to other sites, still leaving some security threats unaddressed. In many examples, security systems were not designed as integrated components of bridge management systems due to the fragmentation of management authority. The operation and management of the systems varies from state to state (Duwadi et al. 2005). Realization of this approach suffers from the 
fractured and intersecting authorities at the federal, state and local levels. Bridge management responsibility is already distributed among TSA, US Coast Guard, US Corps of Engineers (USACE), DOT, and several other entities without clearly identified boundaries. The roles should be defined as to who owns, controls and maintains this integrated system covering many aspects of bridge management and security. However, resolving this administrative issue is beyond the scope of the current paper.

Flexibility is a required property of a security system in order to provide easy adaptation to changing IT technology. Importance of necessary guidelines arises again for the need of establishing standards to be able to connect individual security systems for creating a security network. Incompatible security databases would create problems in the future when the system is compared with that of another site, or when a comprehensive security database is sought. The redundancy and protection of the databases for immediate use during or after major damaging events are key issues.

Protecting the security monitoring systems from being destroyed or disrupted is also a critical issue. Security systems should be designed against an attack and should be robust enough to remain at least partially functional under the extreme conditions during or after a major disaster or a terrorist attack. Another issue is the security of the database containing all security information of the assets, and their protection should be of high concern. For example, the threat of someone tampering with video images prior to them reaching traffic operations personnel is an important factor to be incorporated into the design thinking of bridge security systems. A level of security concern on the transmission of that data or video and a requirement for encryption must be considered especially for the more vulnerable wireless communications links (GAO 2002; Duwadi 2005; US GAO 2003).

\section{CONCLUSIONS}

Recent extreme events such as the terrorist attacks on the United States on September 11, 2001 increased attention on efforts to assess the vulnerabilities of the nation's transportation infrastructure and develop needed improvements in transportation security. Very recently, many other natural disasters have been experienced such as the devastating effects of the Hurricane Katrina in 2005 in the Southeast US. These examples emphasize the need for a more integrated emergency management approach. Transportation agencies are working to modify the current management systems to protect the infrastructure and recover from a terrorist attack with minimum loss. Recent advances in technology offer alternatives to design systems that will allow the engineers, decision makers, emergency responders act rapidly, however lack of guidelines and adequate 
knowledge-base on security considerations as well as shortcomings on funding impedes this prospect.

The ultimate goal is achieving a transportation system that is prepared for and well-protected against man-made or natural threats. A system that can respond efficiently and effectively to natural and man-made disasters and one that can also support transportation, emergency management, and public safety agencies in their efforts moving people and goods in times of emergencies and crises. Recovery from man-made or natural disasters will be more efficient and effective with a resilient transportation system. Implementation of bridge health monitoring as a new approach for bridge management can offer a new alternative for security management. It is shown that bridge health monitoring, decision making and emergency management concepts have to be considered all together for improved security management of bridges as critical components of the transportation network.

\section{ACKNOWLEDGMENTS}

The writers would like to express their sincere gratitude to Prof. A. Emin Aktan (Drexel University) and Prof. Louise K. Comfort (University of Pittsburgh) for their pursuit of multidisciplinary studies which motivated the writers for this paper. Also, the writers would like to thank Ms. Sheila Duwadi, Dr. Steven Chase and Dr Hamid Ghasemi from Federal Highway Administration for their guidance on introducing new technologies for improving bridge security and long-term performance. Finally, the anonymous reviewers all provided valuable contribution with their ideas, and provided important feedback for the paper.

\section{REFERENCES}

AASHTO (2005), Asset Management, http://assetmanagement.transportation.org/

AASHTO/TRB Initiative (2002), "Security and Emergency Response Survey of State Transportation Agencies", NCHRP 20-59(12).

Aktan, A.E. and Comfort, L. (2003), "Management of Multi-Hazards Risk For Metropolitan Regions," Presentation at SPIE's 8th Annual International Symposium on Nondestructive Detection and Measurement for Homeland ecurity and Published in the Proceedings of SPIE, Volume 5048, pp 1-16, San Diego, CA, 2-6 March 2003.

Aktan, A.E. and Faust, D. (2003), "A holistic integrated systems approach to assure the mobility, efficiency, safety and integrity of highway transportation," Keynote Paper, Proceedings of the First International Conference on Structural 
Health Monitoring and Intelligent Infrastructure (SHMII-1'2003), Tokyo, Japan, November 13-15, 2003

Carley, K. and J. Harrald. (1997) “Organizational Learning under Fire.” American Behavioral Scientist. Vol. 3 (January): 310-332.

Catbas, F. N., Lenett, M., Brown, D. L., Doebling, S., Farrar, C. R. and Turer, A. (1997). "Modal Analysis of Multi-Reference Impact Test Data for Steel Stringer Bridges". Proceedings of the 15th International Modal Analysis Conference, Orlando, FL.

Catbas, F. N. and Aktan, A. E. (2002), "Condition and Damage Assessment: Issues and Some Promising Indices." Journal of Structural Engineering, ASCE, 128(8), 1026-1036.

Catbas, F. N., Ciloglu, S. K., Grimmelsman, K. A., Pan, Q., Pervizpour, M. and Aktan, A. E. (2003). "Limitations in Structural Identification of Long Span Bridges". Keynote Presentation and also published in Proceedings of the International Workshop on Structural Health Monitoring of Bridges / Colloqium on Bridge Vibration, Kitami Institute of Technology, Sept 1-2, Japan.

Catbas, F. N., Shah, M., Burkett, J. and Basharat, A. (2004a). "Challenges in Structural Health Monitoring". Proceedings of the 4th International Workshop on Structural Control, A. Smyth and R. Betti, Columbia University, New York.

Catbas, F. N., Brown, D. L. and Aktan, A. E. (2004b), "Parameter Estimation for Multiple-Input Multiple-Output Modal Analysis of Large Structures." ASCE Journal of Engineering Mechanics, 130(8), 921-930.

Catbas, F.N., Brown, D.L., and Aktan, A.E. (2006) "Use of Modal Flexibility for Damage Detection and Condition Assessment: Case Studies and Demonstrations on Large Structures,” Journal of Structural Engineering, ASCE, Vol.132, No 11, pp.1699-1712.

Comfort, L. K., J. Abrams, J. Camillus and E. Ricci. 1989. "From Crisis to Community: The Pittsburgh Oil Spill.” Industrial Crisis Quarterly, Volume 3 (1): 17-39.

CRA Report (2003), "Grand Research Challenges in Information Systems", Computing Research Association, www.cra.org/reports/gc.systems.pdf 
Department of Homeland Security 2004. The National Plan for Research and Development in Support of Critical Infrastructure Protection. www.dhs.gov/xlibrary/assets/ST_2004_NCIP_RD_PlanFINALApr05.pdf

Duwadi, S. R. and Chase, S. B. (2006), "Multiyear Plan for Bridge and Tunnel Security Research, Development, and Deployment", Federal Highway Administration (FHWA) Report No. FHWA-HRT-06-072.

Duwadi, S. R., V. K. Kohli and Eden, J., (2005). Surveillance and Security Technologies for Bridges and Tunnels. International Modal Analysis Conference IMAC XXIII, Orlando, FL.

Earthquake Engineering Research Institute. (EERI). 1949-2003. "Learning from Earthquakes,”Research Program.http://www.eeri.org/earthquakes/LFE/LFE1.html

Earthquake Engineering Research Institute. (2001) "Preliminary Observations on the Origin and Effects of the January 26, 2001 Bhuj (Gujarat, India) Earthquake.” EERI Special Earthquake Report. Learning from Earthquakes Series, April. Pp. 116. http://www.eeri.org.

Farrar, C. R., Sohn, H., Hemez, F. M., Anderson, P., Bement, M. T., Cornwell, P. J., Doebling, S. W., Schultze, J. F., Lieven, N. and Robertson, A. N. (2003), "Damage Prognosis: Current Status and Future Needs", Report LA-14051-MS, Los Alamos National Laboratory, Los Alamos, NM.

Federal Highway Administration (FHWA). (2003) Recommendations for Bridge and Tunnel Security, prepared by The Blue Ribbon Panel on Bridge and Tunnel Security, 2003

Haupt, S. G., Sauntry, W. C. and Rowshan, S. (2005), "Portable Explosive Detection Devices in Transit Environment," Proceedings, TRB 84th Annual Meeting, Jan 2005

Hogue, T. D., Aktan, A. E. and Hoyos, A. (1991), "Localized Identification of Constructed Facilities." Journal of Structural Engineering, ASCE, 117(1), 128148.

ITSA (2002). Supplement to the National ITS Program Plan: A Ten-Year Vision, Homeland Security and ITS, prepared by the Intelligent Transportation Society of America, 2002 
Jain, S. and McLean, C. R. (2006), "An Integrating Framework for Modeling and Simulation for Incident Management." Journal of Homeland Security and Emergency Management, 3(1).

Kauffman, S.A. (1993) "The Origins of Order: Self-Organization and Selection in Evolution." New York: Oxford University Press.

Kreps, G. A. (1994) "Organizing, role enactment, and disaster: a structural theory". Newark: University of Delaware Press.

Levi, A. (1997), "Instrumented Monitoring \& Diagnostic Load Testing for Condition Assessment and Evaluation of Bridges", PhD Thesis, Department of Civil and Environmental Engineering, University of Cincinnati, Cincinnati, $\mathrm{OH}$.

Liu, S.C. and Tomizuka, M. (2003) "Vision and Strategy for Sensors and Smart Structures Technology Research," In Proceedings of the 4th International Workshop on Structural Health Monitoring, Stanford, CA, September 15-17.

Lynch, J.P. and Loh, K. (2005) "A Summary Review of Wireless Sensors and Sensor Networks for Structural Health Monitoring," Shock and Vibration Digest, Sage Publications 38 (2):91-128.

Mileti, D., ed. (1999) " Disasters by Design: A Reassessment of Natural Hazards in the United States," Washington, DC: Joseph Henry Press.

Namkoong, S. J., H. Tanikella and Smith, B. L., (2005). "Design and Field Evaluation of a System Integrating CCTV Surveillance with Video Image Vehicle Detection Systems (VIVDS)," TRB 84th Annual Meeting, Washington D.C

National Cooperative Highway Research Program (NCHRP), Surface Transportation Security, Report No. 525, Volumes 1-6, 2005

National Incident Management Systems (NIMS), Department of Homeland Security, March 2004.

National Response Plan (NRP), Department of Homeland Security, December 2004.

Pack, M. L. and Anderson, P., (2005) "An Open Source, Video-Based, Automatic Incident Detection Program", Proceedings, TRB 84th Annual Meeting, Jan 2005 
Pagano, A. M. and Ogard, E., (2005) "Linking Asset Management to Strategic Planning Processes: Best Practices from State DOT's", Proceedings, TRB 84th Annual Meeting, Jan 2005

PCCIP (1997) President's Commission on Critical Infrastructure Protection, Critical Foundations: Protecting America's Infrastructures, Washington, D.C., 1997. Also available at http://www.pccip.gov/ report_index.html

Platt, Rutherford et al. (1999) "Disasters and Democracy: The Politics of Extreme Events," Washington DC: Island Press.

Port Authority of NY \& NJ, Integration of ITS with Security Systems in a Multimodal Environment, (2002) www.panynj.gov

Quarantelli, E. L. and Dynes (1977). "Disasters: theory and research" London; Beverly Hills, CA: Sage

Quarantelli, E. L., (1992) "Urban Vulnerability and Technological Hazards in Developing Societies," in Environmental Management and Urban Vulnerability, ed. by A. Kreimer and M. Munasinghe (Washington, DC: World Bank. Pp. 187236.

SAIC (2002a). A"ASHTO Security Task Force, National Needs Assessment for Ensuring Transportation Infrastructure Security," prepared by Parsons Brinckerhoff and Science Applications International Corporation (SAIC)

SAIC (2002b) "AASHTO Security Task Force, A Guide to Highway Vulnerability Assessment for Critical Asset Identification and Protection," prepared by Science Applications International Corporation (SAIC)

The White House Report (2003), "The National Strategy for the Physical Protection of Critical Infrastructures and Key Assets, prepared by Department of Homeland Security,"

http://www.dhs.gov/interweb/assetlibrary/HSPD13_MaritimeSecurityStrategy.pdf

US General Accounting Office (GAO) (2003), "Transportation Security Research", http://www.gao.gov/new.items/d021075t.pdf 